\title{
Characteristics of Seismic Hazard in a V-Shaped Valley and Hazard Mitigation Methods
}

\author{
Yan-Ling Qiu', Ling-Kan Yao1,2*, Quan Yuan³ \\ ${ }^{1}$ School of Civil Engineering, Southwest Jiaotong University, Chengdu, China \\ ${ }^{2}$ Road and Railway Engineering Research Institute, Sichuan Key Laboratory of Aseismic Engineering and \\ Technology, Chengdu, China \\ ${ }^{3}$ Xingshu Company, Sichuan Provincial Transport Department, Chengdu, China \\ Email: yaolk@home.swjtu.edu.cn
}

Received 8 March 2015; accepted 19 May 2015; published 22 May 2015

Copyright (C 2015 by authors and Scientific Research Publishing Inc.

This work is licensed under the Creative Commons Attribution International License (CC BY). http://creativecommons.org/licenses/by/4.0/

(c) (i) Open Access

\begin{abstract}
The distribution of hazards triggered by strong earthquakes showed great differences with traditional experience that gained from normal condition or moderate earthquake. This paper researches the differences and discusses the effect on road in V-shaped valleys. The distribution map of slope failures triggered by Lushan earthquake along roads is worked out by detailed investigation. Abnormal areas of seismic hazards are found and marked in the map. Then, co-seismic hazards and post-seismic hazards are researched in detail along Yingxiu-Wolong section of S303 road. V-shaped valleys are abnormal areas in strong earthquakes, where the geological hazards can be extreme large. Rock avalanche is the major type of co-seismic hazard, and debris flow is prone to occur and is the most harmful post-seismic hazard. For new built roads, the line elevation is as high as it can be if the economy and technique are acceptable. In strong earthquake-stricken area, makeshift roads are adopted in damage trunk roads to ensure the traffic. Reconstruction of formal roads should not be started until the end of the active period. The line elevation with enough vertical clearance over the river should be adopted to prevent the post-seismic debris flow hazard.
\end{abstract}

\section{Keywords}

Co-Seismic Hazards, Post-Seismic Hazards, V-Shaped Valley, Route Scheme

\section{Introduction}

In rugged mountainous areas, rivers regions are the most significant topographic features, along which most ${ }^{*}$ Corresponding author.

How to cite this paper: Qiu, Y.-L., Yao, L.-K. and Yuan, Q. (2015) Characteristics of Seismic Hazard in a V-Shaped Valley and Hazard Mitigation Methods. Open Journal of Safety Science and Technology, 5, 27-36. 
human settlements are located. In order to ensure that these settlements have convenient and fast road transportation, and moreover, take full advantage of the natural gradient of riverbed to overcome elevations, roads in mountainous areas extend along riversides as much as possible. This is the basic design principle and common practice for route selection of transportation lines in mountainous areas [1]. However, river valleys are places where a variety of adverse geological phenomena develop. In order to minimize the impact of geological hazards, geological route selection techniques were developed [1]-[3]. Sites with rock masses of higher strength and less discontinuity are less disaster-prone from an engineering point of view. Specifically, intrusive igneous rocks formed under high temperature and pressure such as granite and diorite have very high mechanical strength, little discontinuity and quite good weathering resistance [4]. Roads built in these rock masses experience much less geological hazards, except high in situ stress conditions. In the past few years, several strong earthquakes have happened at the eastern margin of Tibetan Plateau, where stratigraphy and lithology vary greatly. Geological hazards triggered by strong earthquakes have shown great differences in various lithologies, which doesn't conform to traditional experience that gained from normal condition or moderate earthquake. This paper discusses this issue based on the actual situation of seismic hazards.

\section{Abnormal Areas with Seismic Hazards}

Valleys are formed by a process of erosion in the long geological history. Flowing water and its entrained sands cut down into the riverbed to carve out a valley. The forms of valleys can be divided as U-shaped or V-shaped in cross section. A V-shaped valley is a deep, narrow valley with very steep sides. In comparison with a V-shaped valley, the U-shaped valley floor is wider with developed floodplain or fluvial terrace. Most valleys belong to one of these two main types or their mixture [5]. The exact shape depends on the rate of uplift of rock, the type of rock, the type of climate, and the stage of the river. Ultimately, the characteristics of erosive activity determine the type of the valley shape. Valleys with V-shaped cross section are in the youth stage of river development process [6] [7], where erosion cuts downwards more than it does sideways. A valley with U-shaped cross section evolves from V-shaped valley, where erosion cuts sideways more than it does downwards. Along a valley, the cross section usually alternates between V-shaped and U-shaped, as the geological structure varies. Hard rock layers have strong anti-sideways erosion capacity, and they always are V-shaped valleys. Soft rock layers have weak resistance to erosion, so rock layers are worn away fast and U-shaped valleys are evolved into. Because of the lithology, river through hard rock areas such as magmatic, carbonate, breccia and metamorphic rocks, usually form V-shaped valleys.

Earthquakes can trigger all kinds of slope movements. Slope failures such as rock falls, landslides, flows and rock avalanches can occur during seismic shaking. The general distribution situation of these geological hazards triggered by earthquake attenuates with the increase of distance from an epicenter [8]. The scale of geological hazards triggered by earthquake has a close relationship with earthquake intensity. According to empirical data, no slope failure of any significance has been experienced for earthquake intensities <VIII [9]. Specifically, there is hardly any slope failure in intensity of VI, and there are no massive slope failures in intensity of VII. However, geomorphic unit of $\mathrm{V}$-shaped valleys do not meet the above rules. A large number of geological hazards are triggered and serious damages are caused in the abnormal areas.

An earthquake with a magnitude of 7.0 occurred in Lushan, Sichuan, China on April 12, 2013. By these researchers, detailed investigation was carried out on slope failures triggered by the earthquake along national roads, provincial roads and main town roads, which amounted to $300 \mathrm{~km}$ in the earthquake-stricken area. The investigated roads and the distribution of slope failures with a volume of more than $100 \mathrm{~m}^{3}$ are showed in Figure 1. Stratigraphy of outcrops along these roads is marked only strong hard rocks, which mainly distribute in three zones. One is the NE strike Upper Cretaceous-Paleocene Dasi rock group, the lithology is breccia. Three roads include provincial road S210, town roads of Lushan-Shuangshi and Longmen-Taiping cross through this zone. Another is Proterozoic intrusive igneous rocks, Permian and Devonian carbonate rocks, which are extensive outcrops in Lingguan-Fengtongzhai section of road S210. The last one is Proterozoic intrusive igneous rocks distributed in national road G318 and Labahe scenic road.

Two obvious abnormal areas of slope failures along roads appeared in Lushan earthquake. One is Labahe Nature Reserve. It is far from the epicenter, with an earthquake intensity of VI. 12 slope failures are triggered along $14 \mathrm{~km}$ Labahe scenic road, where the lithology is mainly granite and amphibolite metamorphosed from basalt and gabbro. The other one is in accordance with the second zone marked hard rocks, with an earthquake 


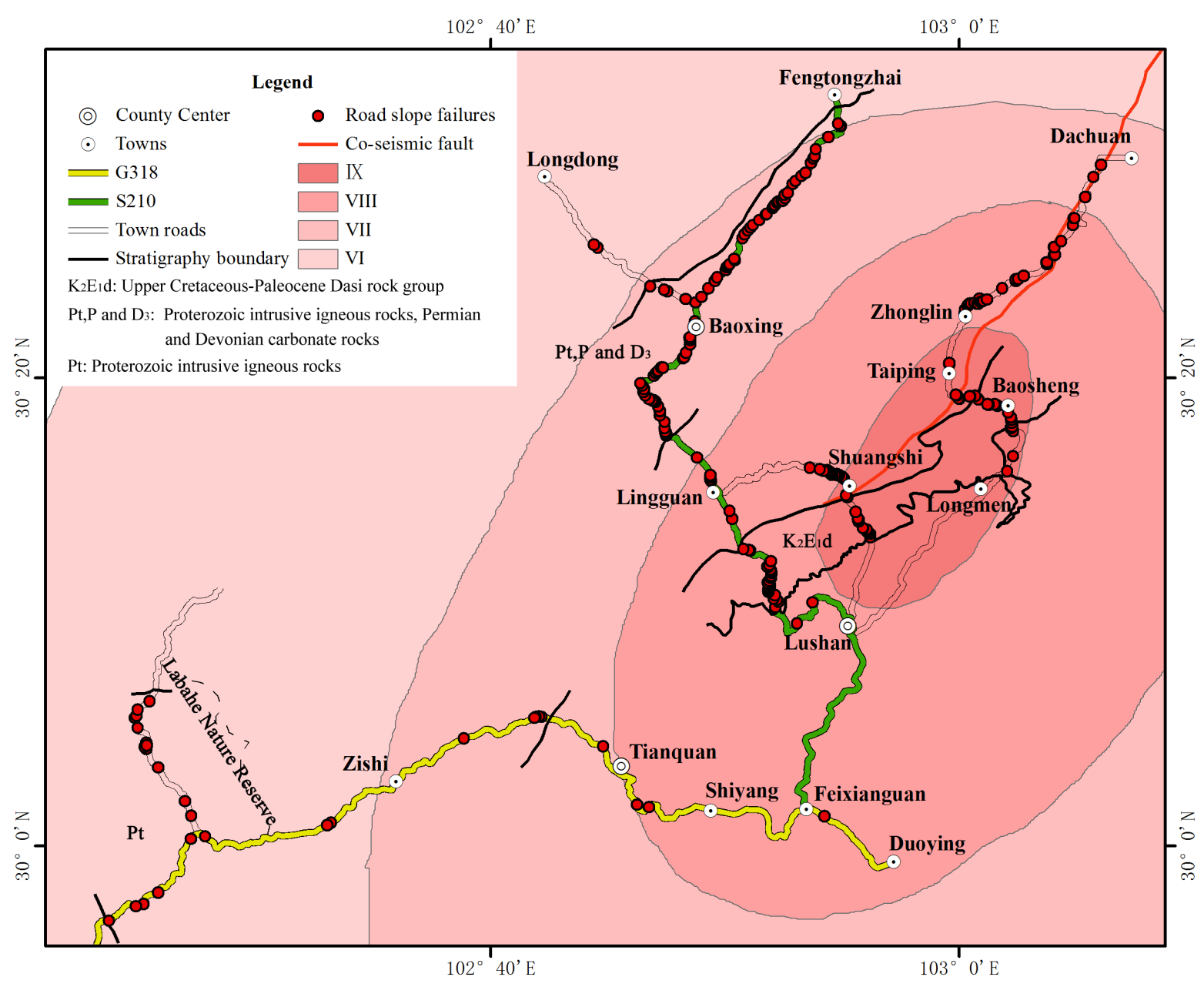

Figure 1. The distribution map of slope failures triggered by Ms7.0 Lushan earthquake along roads.

intensity of VII. Numerous slope failures densely distribute along S210. Slope failures in this area are in greater number and larger than that in the epicenter area with earthquake intensities of IX or VIII. Both of the two abnormal areas are tributary river valleys with V-shaped cross section. The two areas have similar characteristics in lithology and topography, which are strong hard rock lithology and V-shaped valleys topography. The trunk river valley has a longer history of evolution, and therefore has less slope failures.

In addition to the above, V-shaped valley sections of the three roads across Dasi rock group also have large scale seismic slope failures. A large number of seismic slope failures distribute along the line of Dachuan-Shuangshi, because they are zonal distribution along the co-seismic fault.

\section{Co-Seismic Hazards and Related Road Damages in a V-shaped Valley}

Where the earth crust uplifts significantly, the regional erosion and planation are active. As a result, the original rocks buried deeply are gradually approaching and exposing to the surface. In the regional vertical unloading process, once high in suit stress of the original rock is constantly decreasing. A series of near-horizontal unloading fissures are formed in the shallow part of the crust, by unloading rebound. These fissures make the intact rock mass disintegrate, and change the mechanical behavior similarly to layered rock mass [10]. The evolution of the valley is an advanced unloading process of rock mass in regional vertical unloading environment. During the process of valley incising and unloading, the balanced state of rock mass is broke and the stress field is adjusted and redistributed. Because of the stress relief, the slope rock mass takes place unloading rebound towards free-direction of valley and forms fissures [11].

The strong hard rock grade such as igneous, carbonate, breccia and metamorphic rocks has high strength. The 
mechanical response to forces is in a brittle, elastic way [12] [13]. If ultimate strength is reached, the compressive strength is drastically reduced and may even fall to values approaching zero. The brittle behavior implies an almost instantaneous loss of strength with little or no plastic deformation. Because the rock mass can subject to large loads, they can store high strain energy in geomorphic evolution [14]-[16]. During the seismic shaking, the increasing stress adds on the unloading fissures and the total stress reaches to or exceeds the strength limitation. Then the brittle failure occurs. Because of the momentary loading of seismic stress, unloading fissures storing certain strain energy in hard rock mass make brittle fracture to release energy rapidly, resulting in seismic hazards.

A V-shaped valley is in the youth stage of valley evolution process, which is a most active unloading process of geomorphic evolution [6] [7]. Due to earthquake, stress and strain accumulated in unloading fissures in the shallow part of the crust are released in a short time. It ahead and together releases the stress and strain that would release in a period of valley evolution time, and causes serious damages to the surface. Soft rock and semi-hard rock grades have ductile behavior or brittle-ductile behavior. They have lower ultimate strength and higher residual strength than hard rock grade does. With a small load, these rock masses can make deformation and breakage to release unloading stress in evolution process. Therefore, geological hazards easily happen on these rock masses in normal condition or moderate earthquake. But under strong earthquake, rock avalanche triggered in hard rock valley become the most serious hazards.

The Ms 8.0 Wenchuan earthquake occurred at 2:28 pm on May 12, 2008, with the epicenter in Yingxiu, Sichuan, China. Yingxiu-Wolong section of provincial road S303 locates in the epicenter area. It was one of the most seriously damaged trunk roads in the earthquake. Various kinds of geological hazards were triggered along the whole valleys, and road damage phenomena could be seen everywhere.

Yingxiu-Wolong section of provincial road S303 with a total of 45km length is along the left bank of Yuzi Stream. Yuzi Stream is a tributary of Mingjiang River, flowing into the trunk river at Yingxiu. Maoxian-Wenchuan Fault passing through the road in the vicinity of Gengda is the boundary between two geological structures. The geological structure on the northwest side of the fault is Xiaojin fold belt, and the one on the southeast side is Cathaysian structural system. Stratigraphy of outcrops along the road is shown in Figure 2. The downstream of Yuzi Stream is on the southeast of Maoxian-Wenchuan Fault, where widely distributes intermediatemafic intrusive igneous rocks formed in Jinning-Chengjiang period. These igneous rocks are hard biotite granite and granodiorite. Silurian Maoxian rock group in the midstream is soft or semi-hard rock, and the other groups belonging to Xiaojin fold belt are semi-hard rock. Although valley in the downstream goes through the longest time of erosion for Yuzi Stream, the cross sections of the valley are deeper and narrower than that in Silurian

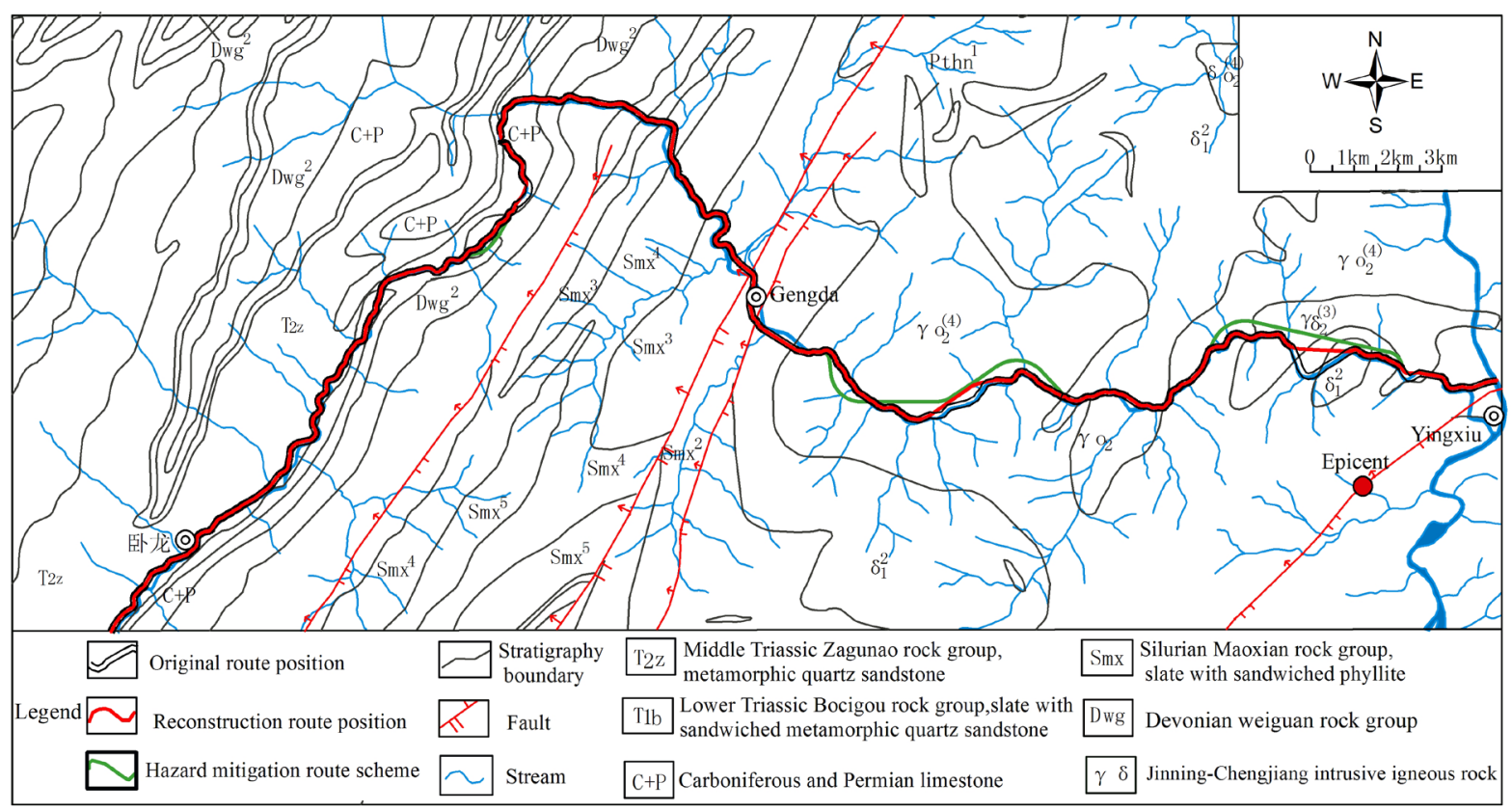

Figure 2. Stratigraphy of outcrops along Yingxiu-Wolong section of provincial road S303. 
Group because of lithology. The valley in the downstream is still typical V-shaped with steep slopes and narrow floor, while the valley in Silurian Group has eroded into U-shaped with a wide floor.

Co-seismic geological hazards along Yuzi Stream were serious. Road S303 along the valley was seriously damaged. Especially in the downstream, where once vegetation-covered slopes widely exposed inner rocks, almost all roads were buried or severely damaged except Panlongshan tunnel and Gengda tunnel. The two sides of Maoxian-Wenchuan Fault provided a startling contrast to co-seismic hazards. On the southeast of the fault, co-seismic hazards were triggered on both sides of the valley continuously. While on the northwest, co-seismic hazards were triggered only on partial limited slopes separately. Co-seismic geological hazards damaged the road on the two sides are shown in Table 1. On the southeast of Maoxian-Wenchuan Fault, the largest scale and the most harmful co-seismic geological hazard was rock avalanche. It rapidly falls masses of rocks and debris that detach themselves from steep slopes. These rock blocks with different sizes deposited in the valley floor and formed quake lakes (Figure 3). Road damage by these rock avalanches was extremely huge. Embankments were buried and bridges were destroyed (Figures 4-6). 46 rock avalanche deposits buried over $10 \mathrm{~km}$ of a total $18 \mathrm{~km}$ length road. Moreover, throughout the road in the downstream region, countless rock falls of various sizes dashed down to the roadbed and made serious damages. Landslide is hardly occurred in igneous rocks zone. There was only one landslide on the upper slope. On the northwest, co-seismic geological hazards decreased substantially. The road damage was negligible. 26 deposits formed by debris avalanche buried about $3 \mathrm{~km}$ of a total $25 \mathrm{~km}$ length road. The three landslides were all old ones reactivated by seismic forces.

Table 1. Co-seismic geological hazards damaged Yingxiu-Wolong section of provincial road S303 on the two sides of Maoxian-Wenchuan Fault.

\begin{tabular}{lcc}
\hline & On the southeast of fault & On the northwest of fault \\
\hline Length of the road (except tunnels) & $18 \mathrm{~km}$ & $25 \mathrm{~km}$ \\
Number of avalanche & 46 rock avalanches \\
Number of landslide & 1 rock landslide \\
Number of quake lake & 7 \\
Number of road washout & 4 & 3 old landslides \\
Number of debris flow & 9 gully-type and 2 slope-type & 2 \\
2
\end{tabular}

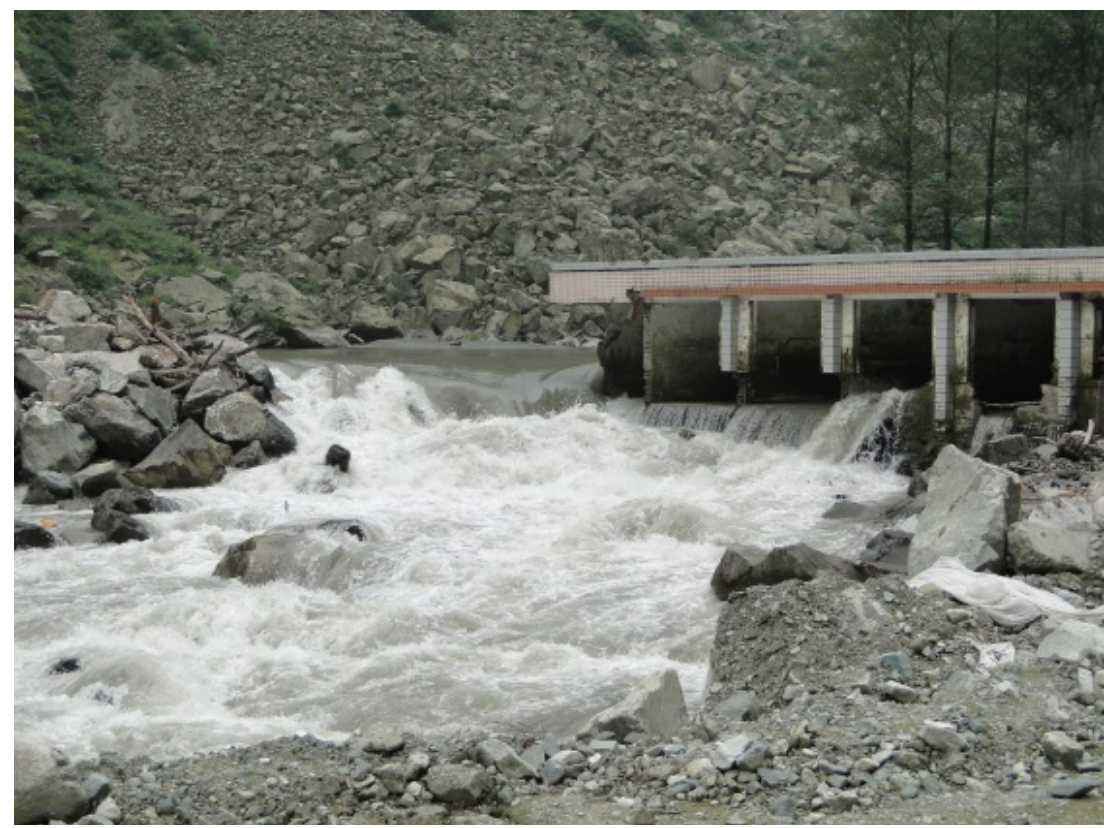

Figure 3. A quake lake formed by rock avalanche deposits submerged a hydropower station. 


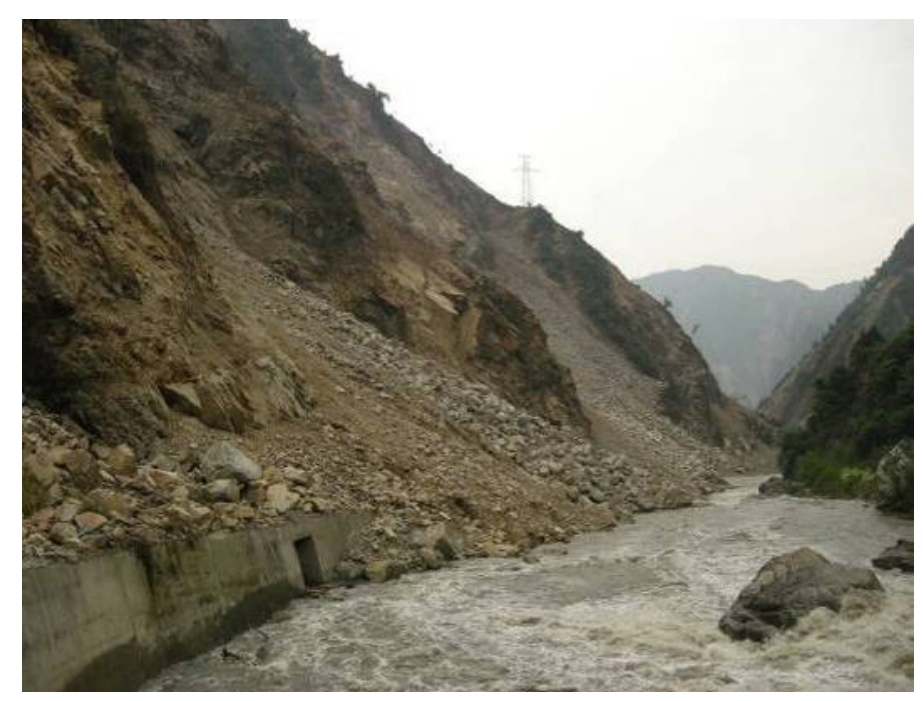

Figure 4. Rock avalanche buried the embankments.

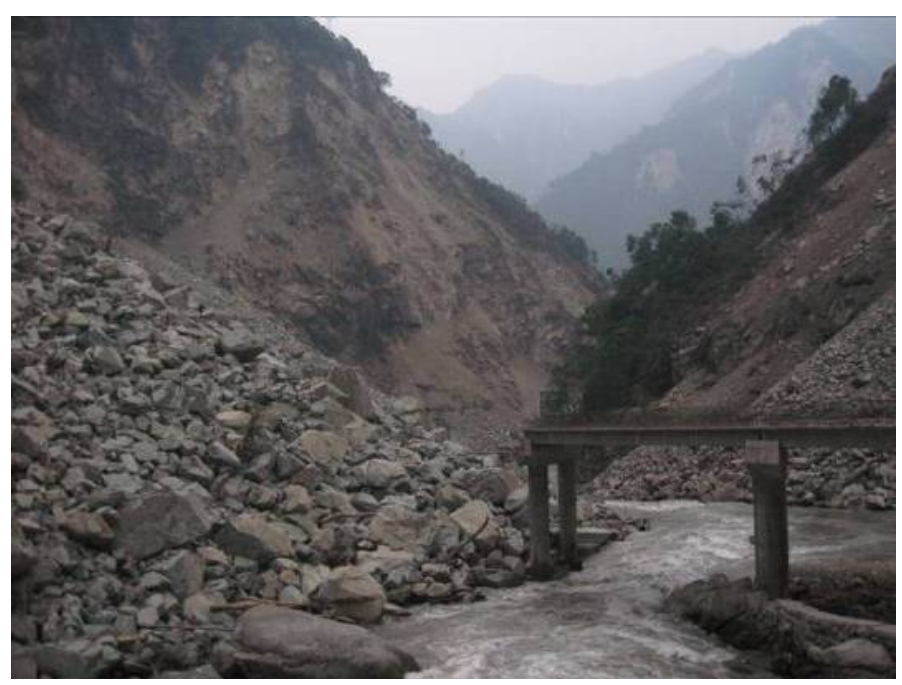

Figure 5. Rock avalanche destoryed the bridge.

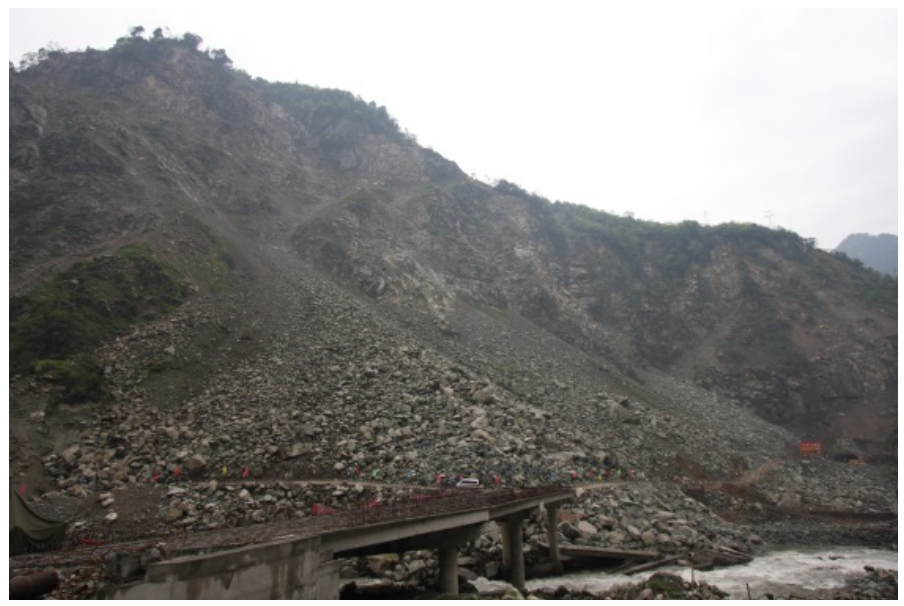

Figure 6. Rock avalanche fell from the steep slopes continuously, destoryed the bridge and buried a large section of road. 


\section{Post-Seismic Hazards and Relating Road Damages in a V-shaped Valley}

After an earthquake in mountainous areas, the commonest geological hazard is rock fall. It usually occurs in places where rock avalanches had once happened. This kind of post-seismic geological hazard always threatens pedestrians and vehicles in a long period. But the most harmful post-seismic hazard for road in V-shaped valley is debris flow triggered by rainstorm.

During the seismic shaking, the pre-existing discontinuity planes such as tectonic, bedding surface, tension cracks extend and rock masses disintegrate to massive blocks on the steep slope surface. These rock blocks provide a wealth of loose materials for the source of debris flows. The rainfall threshold for debris flow is lower than the original level prior to the earthquake [17]. These co-seismic hurt slopes can easily form massive debris flows in the rainstorms. The carrying capacity of a V-shaped valley is negligible because of small volume of narrow valley floor. The rock blocks can hardly be carried away and accumulate in the river, which form dammed lake, rise water lever, change the hydrodynamic conditions. All these hazards significantly threaten the road in the $\mathrm{V}$-shaped valley.

The reconstruction of Yingxiu-Wolong section of road S303 began in May 2009. It was expected to be completed by the end of 2010, with a budget of 811.9 million yuan. The reconstruction project was mainly along the route before Wenchuan earthquake, but newly built 3 tunnels and 6 bridges. The original and reconstruction route are described in Figure 2. Until August 13, 2010, the main structures of reconstruction were completed except one tunnel.

A rainstorm every 130 years hit the area on August 13, 2010, with a rainfall of $160 \mathrm{~mm}$ in eight hours. The extreme rainstorm induced massive debris flows in most tributaries of Yuzi Stream. Along Yinxiu-Wulong section of road S303, 60 debris flows including 32 gully-type and 28 slope-type debris flows damaged the road. Though the scales of debris flows on the two sides of Maoxian-Wenchuan Fault were similar, the road sections on the southeast of fault were more seriously damaged: 24 gully-type and 14 slope-type debris flows. These debris flows deposited on the V-shaped valley floor and formed dammed lakes, which silting river and rising water level. The 3 gully-type debris flows-Xiaojiagou, Xiezigou, and Wasigou-completely clogged the river. The reconstruction project in the length of $6.5 \mathrm{~km}$ was directly buried or submerged. Moreover, large sections indirectly affected had to be abandon. The reconstruction project was totally destroyed.

The Xiaojiagou gully is very close to the portal of newly-built Nanhua Tunnel. An excessive large-scale debris flow of 0.5 million $\cdot \mathrm{m}^{3}$ outbroke in the gully, accumulating together with the slope debris flow near tunnel portal. The deposits buried the entire tunnel portal and stuffed the whole tunnel. The river silted up and the riverbed uplifted $30 \mathrm{~m}$ high. The water level rose above the route elevation more than $20 \mathrm{~m}$ and reached the roof of the tunnel. More than $1 \mathrm{~km}$ length of roadbed was buried and submerged. It was one of the most affected sections by debris flow hazard. Figure 7 and Figure 8 show the portal before and after the event. The Xiaojiagou

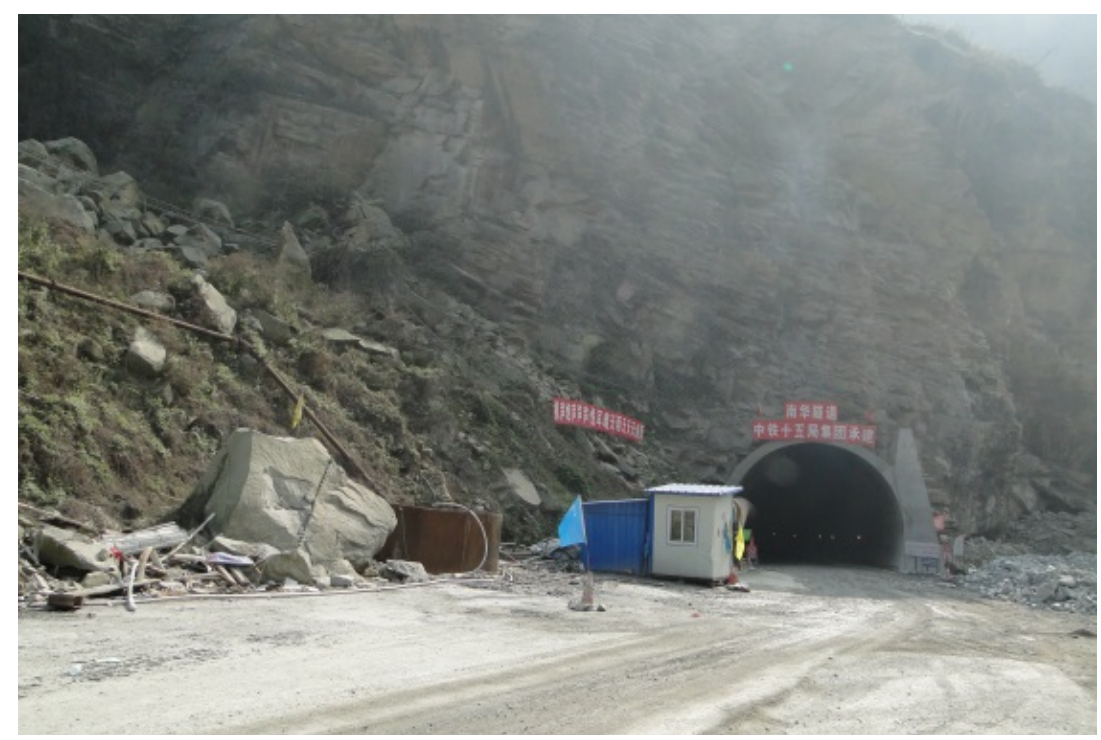

Figure 7. The portal of Nanhua tunnel before August 13, 2010. 


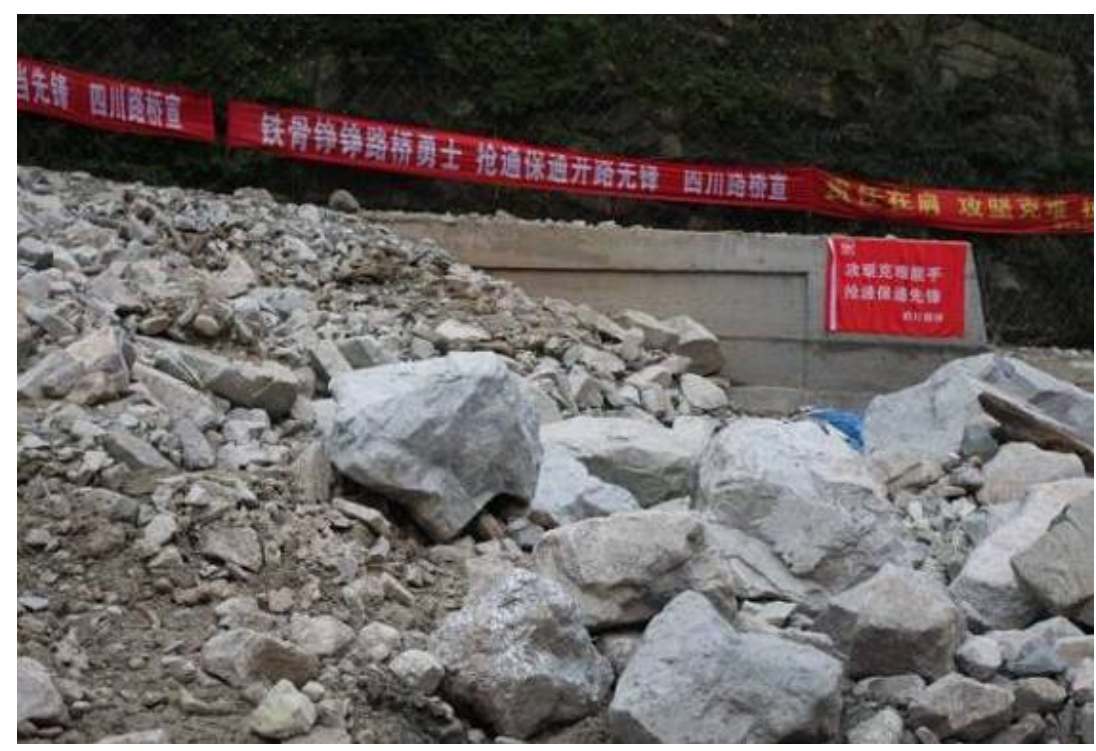

Figure 8. The portal of Nanhua tunnel was buried by debris flow deposits after August 13, 2010.

gully is an old debris flow with a watershed area of $0.24 \mathrm{~km}^{2}$, and there has a debris flow drainage canal before the earthquake. According to a survey, loose or non-consolidated materials for originating were estimated to be up to 3.57 million $\cdot \mathrm{m}^{3}$ after Wenchuan earthquake. The huge material threatened the road continuously.

The Xiezigou was another excessive large-scale debris flow, with a deposit of $0.42 \mathrm{million} \cdot \mathrm{m}^{3}$ at this time. The riverbed uplifted more than $10 \mathrm{~m}$. The dammed lake formed by the deposit submerged not only the road but also the headquarters of the reconstruction. The Xiezigou debris flow had happened once before this time. There is a potential gully debris flow named Xiangjiagou just $250 \mathrm{~m}$ away from Xiezigou. The two close gullies contain loose material with a total volume of $4.01 \mathrm{million} \cdot \mathrm{m}^{3}$.

There were more debris flows on the one valley side such as Wasigou caused serious damage to the road. Moreover, some debris flows occurred on the other side flowed into the river and narrowed the water path. When water was through the narrow river cross-section, it reached to the road side and its velocity increased. As the result of the hydraulics changing, there were washouts along road embankment. Taking into consideration of the existing and potential hazards, route spaces had to shift up from the valley to mountain and raise line elevation substantially (show in Figure 2).

\section{Suggestion for Hazard Mitigation Methods}

Route selection in high earthquake intensity mountainous areas is a multi-objective decision-making process. It co-ordinates the contradiction between saving investment and reducing seismic hazard risk in the future. The concept of risk-control must be maintained consistently and systematically in the whole process of route selection. In V-shaped valleys, the location of road is influenced in the first instance by topography. Generally, the location makes use of the narrow zonal topography that is fluvial terrace or accumulation area on foot slope. As a result, the road line elevation is little higher than the water level. It is the project with the least cost, labor work, as well as the influence on geological environment. But such project usually has less hazard-resistant capacity. In order to increase the hazard-resistant capacity, the location of highway and railway avoids hazard-prone foot slope by location adjustment in the plane and elevation, by taking advantage of bridges and tunnels. Otherwise, corrective or stabilization measures are adopted to prevent hazards and mitigate damages. For new road, the scheme with higher line elevation is better than the other schemes, when the differences of economy and technique are in the acceptable range.

In strong earthquake-stricken area, it is not suitable for engineering construction in the active period of postseismic hazards. The conclusion is learned from a profound lesson of the reconstruction project of S303. Transportation is the basic of the recovery after an earthquake. Makeshift roads are adopted in damage trunk roads to ensure the traffic. Reconstruction of formal roads shall be delayed until the end of the active period. Roads in 
V-shaped valley need pay attention to post-seismic debris flow hazard, which may form dammed lake and rise the water level substantially. The design of the basic line elevation needs a series of study on the hazard: A survey on the amount of material source, a calculation of the deposit in recovery period, an estimate of the rising water level. Earthquake shaking generates a lot of fresh discontinuities and expands the pre-existing discontinuities in inner hard rock. These discontinuities expand in the weathering process, and finally disintegrate into blocks and fall down. Rock fall is the most common and the longest duration hazard after an earthquake. Structures stabilization or protection against rock fall shall be considered in design to mitigate the damage, and tunnels are proposed to avoid areas of rock fall.

Recovery after an earthquake is a long-term process. A comprehensive recovery includes physical recovery, economic recovery and life recovery. Among of them, physical recovery is the base of the other two [18] [19]. Natural environment deteriorates after the earthquake, especially in mountainous valleys [20] [21]. The initial years after the strong earthquake become a very active period of post-seismic hazards that large-scale geological hazards occur constantly, because of the massive loose materials. Research has shown that the active period may last 5 years in earthquake intensity of X and XI [22]. Vegetation effectively helps to prevent soil erosion, so vegetation coverage reflects this active period to some extent. Data of some events indicates that the vegetation recovery process needs several years or more [23]-[25]. Over time, the number and the activity of unstable slopes are decreasing. But it also needs enough time to recover to the original level, which is decade for landslides, and is more for debris flows in earthquake intensity of X and XI [22].

\section{Summary}

Geomorphic unit of V-shaped valleys are abnormal areas in strong earthquakes, where the geological hazards can be extreme larger than other places. Because of the storage of high strain energy and brittle behavior of the rock mass, co-seismic hazard of rock avalanche are triggered massively in V-shaped valleys. As a wealth of loose materials, rainstorms trigger massive debris flows. Because of the negligible carrying capacity, debris flows become the most harmful post-seismic hazard for road in V-shaped valleys. For new built roads, the line elevation is as high as it can be if the economy and technique are acceptable. For strong earthquake-stricken area, makeshift roads are adopted in damage trunk roads to ensure the traffic. Reconstruction of formal roads should not be started until the end of the active period. The line elevation with enough vertical clearance over the river should be adopted to prevent the post-seismic debris flow hazard.

\section{Acknowledgements}

The study is supported by the Research and Development of Science and Technology Project of China Railway Corporation (Grant No. 2013G014-A and No. 2014G004-A).

\section{References}

[1] He, Z.N. (2010) On Geological Location and Main Technical Principles for Railway. In: Zhu, Y., Ed., Proceedings of Railway Location and Overall Design in Complex Mountainous Area, China Railway Press, Beijing, 97-102.

[2] Konietzky, H., te Kamp, L., Hammer, H. and Niedermeyer, S. (2001) Numerical Modelling of in Situ Stress Conditions as an Aid in Route Selection for Rail Tunnels in Complex Geological Formations in South Germany. Computers and Geotechnics, 28, 495-516. http://dx.doi.org/10.1016/S0266-352X(01)00009-X

[3] Podverbniy, V. and Filatov, E. (2012) Design of Protective Constructions on East Siberian Railway. The 3rd International Symposium on Innovation and Sustainability of Modern Railway, Nanchang, 20-21 September 2012, 206-215.

[4] Bell, F.G. (2007) Engineering Geology. 2nd Edition, Butterworth-Heinemann, Oxford.

[5] Pavlopoulos, K., Evelpidou, N. and Vassilopoulos, A. (2009) Mapping Geomorphological Environments. SpringerVerlag, Berlin. http://dx.doi.org/10.1007/978-3-642-01950-0

[6] Strahler, A.N. (1952) Hypsometric (Area-Altitude) Analysis of Erosional Topography. Geological Society of America Bulletin, 63, 1117-1142. http://dx.doi.org/10.1130/0016-7606(1952)63[1117:HAAOET]2.0.CO;2

[7] Schumm, S.A. (1973) Geomorphic Thresholds and Complex Response of Drainage Systems. In: Morisawa, M., Ed., Fluvial Geomorphology, Publications of Geomorphology, State University of New York, Binghamton, 299-310.

[8] Cui, P., Chen, X.Q., Zhu, Y.Y., Su, F.H., Wei, F.Q., Han, Y.S., Liu, H.J. and Zhuang, J.Q. (2011) The Wenchuan Earthquake (May 12, 2008), Sichuan Province, China, and Resulting Geohazards. Natural Hazards, 56, 19-36. http://dx.doi.org/10.1007/s11069-009-9392-1 
[9] Vallejo, L.G. and Ferrer, M. (2011) Geological Engineering. CRC Press, London.

[10] Tao, M., Li, X.B. and Wu, C.Q. (2012) Characteristics of the Unloading Process of Rocks under High Initial Stress, Computers and Geotechnics, 45, 83-92. http://dx.doi.org/10.1016/j.compgeo.2012.05.002

[11] Xia, M. and Ren, G.M. (2013) Characteristics and Mechanism of Concentrated Unloading in Bank Slope of Yangqu Hydropower Station. Journal of the Geological Society of India, 82, 421-429. http://dx.doi.org/10.1007/s12594-013-0169-5

[12] Wawersik, W.R. and Fairhurst, C. (1970) A Study of Brittle Rock Fracture in Laboratory Compression Experiments. International Journal of Rock Mechanics and Mining Sciences, 7, 561-575. http://dx.doi.org/10.1016/0148-9062(70)90007-0

[13] Miao, J.L., Jia, X.N. and Cheng, C. (2011) The Failure Characteristics of Granite under True Triaxial Unloading Condition. Procedia Engineering, 26, 1620-1625. http://dx.doi.org/10.1016/j.proeng.2011.11.2346

[14] Yin, Z.Q., Li, X.B., Jin, J.F., He, X.Q. and Du, K. (2012) Failure Characteristics of High Stress Rock Induced by Impact Disturbance under Confining Pressure Unloading. Transactions of Nonferrous Metals Society of China, 22, 175184. http://dx.doi.org/10.1016/S1003-6326(11)61158-8

[15] Hua, A.Z. and You, M.Q. (2001) Rock Failure due to Energy Release during Unloading and Application to Underground Rock Burst Control. Tunnelling and Underground Space Technology, 16, 241-246. http://dx.doi.org/10.1016/S0886-7798(01)00046-3

[16] Tao, M., Li, X.B. and Li, D.Y. (2013) Rock Failure Induced by Dynamic Unloading under 3D Stress State. Theoretical and Applied Fracture Mechanics, 65, 47-54. http://dx.doi.org/10.1016/j.tafmec.2013.05.007

[17] Shieh, C.L., Chen, Y.S., Tsai, Y.J. and Wu, J.H. (2009) Variability in Rainfall Threshold for Debris Flow after the ChiChi Earthquake in Central Taiwan, China. International Journal of Sediment Research, 24, 177-188. http://dx.doi.org/10.1016/S1001-6279(09)60025-1

[18] Hayashi, H. (2009) Long-Term Disaster Recovery Processes: Lessons Learned from the 1995 Kobe Earthquake. International Conference on Earthquake Engineering, The First Anniversary of Wenchuan Earthquake, Chengdu, 9-12 May 2009, 670-676.

[19] Frazier, A.E., Renschler, C.S. and Miles, S.B. (2013) Evaluating Post-Disaster Ecosystem Resilience Using MODIS GPP Data. International Journal of Applied Earth Observation and Geoinformation, 21, 43-52. http://dx.doi.org/10.1016/j.jag.2012.07.019

[20] Wang, Z.Y., Cui, P. and Wang, R.Y. (2009) Mass Movements Triggered by the Wenchuan Earthquake and Management Strategies of Quake Lakes. International Journal of River Basin Management, 7, 391-402. http://dx.doi.org/10.1080/15715124.2009.9635397

[21] Di, B.F., Zeng, H.G., Zhang, M.H., Ustin, S.L., Tang, Y., Wang, Z.Y., Chen, N.S. and Zhang, B. (2010) Quantifying the Spatial Distribution of Soil Mass Wasting Processes after the 2008 Earthquake in Wenchuan, China: A Case Study of the Longmenshan Area. Remote Sensing of Environment, 114, 761-771. http://dx.doi.org/10.1016/j.rse.2009.11.011

[22] Cui, P., He, S.M., Yao, L.K., Wang, Z.Y. and Chen, X.Q. (2011) Formation Mechanism and Risk Control of Mountain Hazards Induced by Wenchuan Earthquake. Science Press, Beijing.

[23] Lin, W.T., Lin, C.Y. and Chou, W.C. (2006) Assessment of Vegetation Recovery and Soil Erosion at Landslides Caused by a Catastrophic Earthquake: A Case Study in Central Taiwan. Ecological Engineering, 28, 79-89. http://dx.doi.org/10.1016/j.ecoleng.2006.04.005

[24] Lin, C.Y., Lo, H.M., Chou, W.C. and Lin, W.T. (2004) Vegetation Recovery Assessment at the Jou-Jou Mountain Landslide Area Caused by the 921 Earthquake in Central Taiwan. Ecological Modelling, 176, 75-81. http://dx.doi.org/10.1016/j.ecolmodel.2003.12.037

[25] Lin, W.T., Chou, W.C. and Lin, C.Y. (2005) Vegetation Recovery Monitoring and Assessment at Landslides Caused by Earthquake in Central Taiwan. Forest Ecology and Management, 210, 55-66. http://dx.doi.org/10.1016/j.foreco.2005.02.026 